\title{
Forming and developing engineering technology as a science
}

\author{
Anatoly G. Suslov ${ }^{1, *}$, and Dmitry I. Petreshin ${ }^{1}$ \\ ${ }^{1}$ FSBEI of Higher Education "Bryansk State Technical University", 241035, Bryansk, Boulevard 50 \\ letiya Oktyabrya 7, Russia
}

\begin{abstract}
The origin of engineering technology and its formation as a science is stated. The stages of developing engineering technology and the names of scientists who have made a significant contribution to this development are given. The scientific directions of engineering technology further development are defined.
\end{abstract}

Mechanical engineering technology as a science is designed to develop and improve the theory of technological support and increase the quality of engineering products at the lowest cost or the highest productivity of their manufacturing $[1,2]$.

Improving and developing new theoretical provisions should be based on the latest achievements of science and technology for the given period of time. An example can be improving the theory of the roughness parameter formation during machining. At the beginning of the $\mathrm{XX}^{\text {th }}$ century it was presented that forming the roughness parameter was due to the radius at the top of the cutter and the kinematics of its movement on the treated surface. In the middle of $\mathrm{XX}^{\text {th }}$ century one began to take into account that the main and auxiliary angles in terms of the cutter influenced the roughness parameter formation of the treated surface during machining, depending on the ratio of the radius at the top of the cutter and the feed. At the end of the $\mathrm{XX}^{\text {th }}$ century in the theoretical description of the roughness parameter of the machined surface it was considered that plastic deformation of the material in the cutting zone, the elastic vibrations of the technical system and the roughness of the cutting edge of the cutter along with the geometry and kinematics of the cutter movement influence the machined surface formation. At the same time, this theory of roughness formation of the treated surface was extended to all methods of machining: blade, diamond-abrasive and supporting and the basic reference designation FPM (forming pressure maintenance).

At the same time, theoretical studies on forming the roughness of the treated surfaces are carried out in two directions:

1) classical direction, implemented by Bryansk and Sevastopol scientific and technological schools. It consists in the theoretical representation of the physical picture of forming the roughness parameters of the part surface during machining and its mathematical description;

\footnotetext{
* Corresponding author: naukatm@yandex.ru
} 
2) theoretical description of the formed surface roughness of the workpiece during machining using the similarity method (implemented by Rybinsk scientific technological school).

Mechanical engineering technology is an applied science caused to life by the needs of industry.

It went through several stages in its development.

1. The previous stage is the practical experience accumulated by mankind for thousands of years.

2. The preparatory phase is since the appearance of the first lathes and drilling machines with manual drive in the twelfth century to the seventeenth century.

3. The cumulative stage (XVII - XIX centuries) is characterized by the accumulation of domestic and foreign production experience of manufacturing machines. In the late XVII ${ }^{\text {th }}$ - early XIX ${ }^{\text {th }}$ centuries technical journals and brochures published the descriptions of treatment processes of various parts, used equipment and tools. The accumulated experience was first described in 1807 by Professor of Moscow University V.I. Dvigubskiy in the book, "The rudiments of technology or brief description of the work at the plants and factories".

4. The first scientific stage (for Russia it is 1880 - 1940) is characterized by generalization and systematization of production experience and the beginning of developing the General scientific principles of constructing technological processes. This includes the writings of Professors I.I. Thieme, A.P. Gavrilenko, A.P. Sokolov, A.I. Kashirin, V.M. Cowan, A.I. Yahin. As a result of these works in 1940 there came out the resolution of Council of people's Commissars of the USSR "about observance of technological discipline at machine-building plants" that played a big role in improving the quality of military equipment.

5. The second scientific stage (1941 - 1970) is characterized by developing new technological ideas. There were formed the theory of precision machining (Professors A.P. Sokolov, B.S. Balakshin, V.M. Cowan, I.M. Kolesov, V.S. Korsakov); the surface quality and its influence on operational properties of machine parts (Professors P.E. Dyachenko, M.A. Elizavetin, A.I. Isayev, A.M. Sulima, Z.V. Ryzhov, A.M. Matalin, I.V. Kragelsky, A.S. Pronikov, E.A. Satel); the theory of technological inheritance (Professors A.M. Daliski, P.I. Yascheritsin). Various methods of processing are investigated in detail: blade (Professors G.I. Granovsky, N.N. Zorev, I.A. Kogan, B.A. Kravchenko, T.I., Loladze, A.D. Makarov, V.I. Poturaev, A.I. Isaev, N.I. Reznikov, P.R. Rodin, S.S. Silin, N.V. Talantov, etc); abrasive (Professors A.V. Yakimov, L.V. Khudobin, E.N. Maslov, S.A. Popov, M.F. Semko, etc.); finishing-strengthening processing of FPM (Professors P.G. Alekseev, E.G. Konovalov, I.V. Kudryavtsev, D.D. Papshev U.G. Proskuryakov, A.A. Khvorostukhin, G. Schneider, D.N. Yudin). A group technology was developed (Professor S.P. Mitrofanov), adaptive management (Professors B.S. Balakshin, M.Y. Solomentsev, B.M. Bazrov), scientific bases of assembly (Professors M.P Novikov, V.S. Korsakov).

The first result of these studies and the formation of engineering technology as a science was the book by A.P. Sokolovsky "Scientific basis of engineering technology" (1955) [1].

6 . The third research stage $(1970-2000)$ is characterized by the wide use of achievements of fundamental Sciences and computing engineering technologies (Professors V.I. Averchenkov, N.M. Kapustin, V.P. Mitrofanov, A.V. Oleinik, V.V. Pavlov, Y.M. Solomentsev, V.A. Timiryazev, V.D. Tsvetkov). The theoretical level of mechanical engineering technology increased significantly (Professors A.P. Babichev, B.M. Bazrov, A.M. Barzov, V.F. Bezhyazichniy, P.I. Belyanin, V.I. Butenko, A.S. Vasilev, L.A. Gik, O.A. Gorlenko, A.A. Gusev, A.M. Dalsky, D.G. Evseev, V.B. Ilitskiy, L.I. Karpov, A.V. Kirichek, A.A. Kolobov, S.A. Korchak, M.G. Kosov, Z.I. Kremen', V.N. Latyshev, V.V. Michitanki, A.N. Mikhailov, Y.K. Novoselov, Y.F. Nazarov, A.N. Ovsienko, V.M. 
Orobinsky, V.A. Astafiev, M.E. Popov, A.A. Ryzhkin, N.M. Sultan-zade, V.M. Smelyanskiy, V.K. Starkov, Yu.S. Stepanov, A.G. Suslov, M.A. Tamarkin, A.G. Skhirtladze, N.Uh. Ternuk, A.V. Totay, A.P. Ulashkin, V.P. Fedorov, A.S. Yamnikov).

Released in 1973, the new GOST (Government Statement) on roughness parameters (GOST 2789-73) intensified scientific research on technological support and the quality increase of the surface layer and the performance properties of machine parts and their compounds. This included the works of professors Bezhyazichniy V.F., Ryzhov E.V., Silina S.S., and Sulima A.M., Gorlenko O.A., Gorlenko A.O., Suslov A.G., Fedorov V.P., Tatay A.V., Starkov V.K., Novoselov Yu.K., Kozhina T.D., Handoko A.V., Fedonin O.N.

The electro-physico-chemical, plasma, ion, laser, ultrasound and combined methods of treatment are developed and thoroughly researched (Professors V.A. Barvinok, Yu.P. Bochkarev, A.N. Boldyrev, A.G. Grigoryants, S.A. Klimenko, V.M. Prikhodko, A.M. Markov, V P. Smolentsev, etc.). The new methods of mechanical processing are improved and created: needle cutting, vibrorolling, centrifugal impact processing, vibrating processing, processing by a diamond tool, pulse-shock treatment, mandrelling (Professors A.P. Babichev, S.A. Zaides, A.V. Kirichek, A.A. Ryzhkin, A.V. Totay, Yu.V. Proskuryakov, Y.G. Schneider, etc.).

The self-oscillation of technological equipment and its influence on the quality of machine parts are thoroughly studied (Professor B.M. Brzhozovsky, etc.).

The results of these works have been summarized and partially reflected in the Encyclopedia "mechanical engineering", published by the publishing-house "Engineering" in 2000, volume III-3, "Technology of manufacturing machine parts". In 2002 the monograph written by A.G. Suslov, A.M. Dalsky "Scientific Fundamentals of Engineering Techniques" was published [2].

7. Currently, the fourth scientific stage of developing engineering technology is being implemented.

The systematization of scientific schools and directions in engineering technology is carried out. In 2006 the encyclopedia Technologists of Russia (mechanical engineering) is published [3], which gives the names of scientists who have made a significant contribution to developing mechanical engineering technology; the information on the scientific technological schools formed by this time and the direction of their scientific work. The encyclopedia sets out the main directions of engineering technology further development.

1) Improving and optimizing existing and developing new energy - and material-saving technological processes of manufacturing engineering products.

2) Improving and optimizing existing and developing new high-tech combined technological methods of processing blanks, including new materials.

3) developing environmentally friendly methods and technological processes of manufacturing products.

4) Developing methods for producing process fluids related to metal processing.

5) Technological modification of surface layers and restoration of machine parts sizes.

6) Technological creation is natural to varying optimal quality of the workpiece surface on the basis of its functional purpose.

7) High-precision, precision and nanotechnology, allowing to ensure the accuracy of the processing about 10 Angstrom and to obtain a surface with a roughness $\mathrm{Rz}=0.001$ microns.

8) High-speed processing methods.

9) Technological heredity in material properties, size accuracy and quality of the surface layer of parts from the production of materials to operation.

10) Improving design and technological dimensional analysis of mechanical engineering products taking into account the quality of the mating surfaces and its full automation. 
11) Technological support and improving the operating properties of machine parts and their compounds, i.e. developing functionally-oriented technologies.

12) Adaptive quality management of machined parts and assembled products.

13) Creating self-learning technological systems.

14) Improving existing and developing new technological methods of assembly.

15) Creating the element base of technological support for manufacturing parts and assembly of products.

16) Integrating design, manufacturing, operation, repair and disposal technologies into a single process.

17) New technology of parts creation by cultivation (prototyping).

18) Improving the CAD system of technological processes and creating GALS (Continuous Acquisition and LifeCycle support) technologies.

19) Developing the methods of constructing the technological processes, means of technological equipment, their typification and unification, methods of organizing the technological and production processes of the parts, manufacturing and products assembly on the principles of modular technology.

20) Typification and unification of technological support from the standpoint of a systematic approach.

21) Developing the technological projects for the optimal re-equipment of machinebuilding industries for the purpose of their intensification, flexibility and competitiveness.

22) Optimizing the technological processes of producing large-size parts.

23) Technological environments and self-organizing technological systems.

24) Technologies of processing the blanks for computer-integrated flexible engineering industries.

25) Technological processes of manufacturing machine parts from non-metallic materials.

Given that in the Soviet Union and Russia there were developed and created many different methods of finishing-hardening treatment by surface plastic deformation, encyclopedia of surface plastic deformation was published in 2015 [4]. The use of these encyclopedias allows machine-building enterprises to directly address to the leading scientists and scientific schools for having scientific solutions to emerging problems.

The wide application of composite materials led to studying the cutting processes of these materials. These works are carried out in MSTU named after N.E. Bauman (V M. Yaroslavtsev), St. Petersburg Polytechnic Institute (Y.M. Zubarev), Perm national research University (V.F. Makarov), etc.

In connection with the wide application of titanium alloys the method of creep cutting is being developed (by Professors S.M. Chan, V.F. Makarov, Y.K. Novoselov, etc.); grinding by highly porous circles (by Professors V.A. Nosenko, V.K. Starkov, etc.).

There was formed the direction aimed at unifying the technologies of design, manufacture and operation of machines and at developing scientific bases for system creation of new technological methods of processing, including mechanical and physicochemical ones, allowing to provide the necessary performance properties of machine parts; and the direction is aimed at modifying the surface layers of parts and developing functionally-oriented technologies and the modular principle of constructing the technological processes (Professors V.F. Bezhyazichniy, V.P. Smolentsev, A.G. Suslov, A.O. Gorlenko, O.N. Fedonin, B.M. Bazrov, A.N. Mikhailov, A.M. Markov, A.A. Sitnikov, P.Y. Bochkarev, etc.).

Additive technologies, CALS-technologies and automation of all production processes are beginning to develop actively. Their unification allows approaching to developing and creating digital productions. 
Various programs of Russia's technological development are actively discussed. Realizing the great role of engineering technology in this development, in 2008 the Association of machine-building technologists was created, which is designed to consolidate the scientific technological schools of Russia for further scientific development of engineering technology. Given that in these years, technologists began to be called various managers, there appeared the expressions in the society ("high technology", "critical technology", etc.). Realizing the perversion of these definitions in 2011 there was created a new magazine "Science-intensive technologies in mechanical engineering" in the publishing house "mechanical engineering" on the initiative of the Association of mechanical engineers. Science-intensive technologies in mechanical engineering are understood as technologies based on the latest achievements of science and technology. On the basis of generalizing science-intensive technologies on various technological repartitions the monograph "Science intensive technologies in mechanical engineering" is published [5].

International scientific and technical conferences are held annually in this direction in various cities.

\section{References}

1. A. P. Sokolovsky, Scientific basis of engineering technology (M.: Mashgiz, 1955)

2. A. G. Suslov, A. M. Dalsky, Scientific Fundamentals of Engineering Techniques (M.: Engineering, 2002)

3. A. G. Suslov, V. V. Bushuev, V. A. Grechishnikov, V. P. Smolentsev, Encyclopedia. Technologists of Russia (mechanical engineering). Vol. 1. Engineering technology, machines and tools/ ed. by A.G. Suslov (M.: Engineering, 2006)

4. Encyclopedia of surface plastic deformation / ed. by Dr. Engin. Sciences, prof. S.A. Zades (Irkutsk: Publishing house of Irkutsk National Research Technical University, 2015)

5. A.G. Suslov, B.M. Bazrov, B.F. Bezhyazichniy, et al., Science intensive technologies in mechanical engineering/; ed. by A.G. Suslov (Moscow: Machine Building, 2012) 